\title{
TAMAN PANCA YADNYA DALAM UPAYA KONSERVASI TANAMAN UPACARA AGAMA HINDU DI KEBUN RAYA BALI
}

\author{
Dyan M.S. Putri ${ }^{1}$
}

\begin{abstract}
ABSTRAK
Pemanfaatan tanaman sebagai tanaman sebagai tanaman upacara atau dikenal dengan 'tanaman upakara' merupakan salah satu elemen pokok bagi umat Hindu di Bali. Sebagai lembaga konservasi, Kebun Raya Bali telah melakukan kegiatan kegiatan eksplorasi dan pengkoleksian tanaman upacara. Data Januari 2020 koleksi tanaman yang tertata di Taman Panca Yadnya sebanyak 62 suku, 139 marga, 205 jenis dan 1.212 spesimen. Kegiatan penelitian juga telah dilakukan dengan menggali informasi tentang pemanfaatan tanaman upacara agama Hindu Bali. Tercatat sebanyak 30 jenis tanaman upacara agama Hindu Bali 30 jenis yang termasuk dalam tanaman yang berstatus konservasi (Redlist IUCN). Untuk itu masih perlu dilakukan kegiatan konservasi dan penggalian informasi potensi tanaman upacara agama Hindu Bali dapat dimanfaatkan secara optimal tanpa menyebabkan kepunahan.
\end{abstract}

Kata kunci: Konservasi, Kebun Raya Bali, tanaman upacara, Taman Panca Yadnya

\begin{abstract}
Utilization of plants as plants as ceremonial plants or known as 'upakara plants' is one of the main elements for Hindus in Bali. As a conservation institution, Bali Botanic Garden has carried out exploration and collection of ceremonial plants. January 2020 data collection of plants arranged in Taman Panca Yadnya are 62 families, 139 generas, 205 species and 1,212 specimens. Research activities have also been carried out by digging up information on the use of Balinese Hindu religious ceremonies. 30 species of Balinese Hindu religious ceremonies were recorded, 30 of which were included in the conservation status plants (IUCN Redlist). For this reason, it is still necessary to carry out conservation activities and extract information on the potential plants of Balinese Hindu religious ceremonies that can be utilized optimally without causing extinction.
\end{abstract}

Keywords: Conservation, Bali Botanic Garden, ceremonial plants, Taman Panca Yadnya

\section{PENDAHULUAN}

Pada masyarakat Hindu Bali, pemanfaatan tanaman sebagai tanaman upacara atau dikenal dengan 'tanaman upakara' merupakan salah satu elemen pokok bagi umat Hindu di Bali. Sebagian besar kegiatan upacara tersebut membutuhkan sarana yang berasal dari tumbuh-tumbuhan, Unsur bunga diolah sedemikian rupa ditambah dedaunan serta buah-buahan sehingga menjadilah canang sari, daksina, dan lain sebagainya (Armeini, W. A. 2018).

Kebun Raya Balisebagai lembaga konservasi berperan penting dalam pelestariannya (Warseno, dkk. 2013). Adanya Taman Panca Yadnya sebagai taman koleksi tematik merupakan salah satu bentuk konservasi yang dilakukan Kebun Raya 'Eka Karya' Bali. Koleksi taman tematik ini diperoleh dari hasil eksplorasi di seluruh kawasan Bali dan menggali informasi ke masyarakat tentang pemanfaatannya. Saat ini tumbuhan upacara adat koleksi Kebun Raya "Eka Karya" Bali

\footnotetext{
${ }^{1}$ Peneliti Balai Konservasi Tumbuhan Kebun Raya Bali-LIPI, Email: dyan.ari79@gmail.com
} 
sebanyak 62 suku, 139 marga, 205 jenis dan 1.212 spesimen (data Registrasi Koleksi Januari 2020).

Penulisan makalah ini bertujuan untuk memberikan informasi tentang pengelolaan dan usaha konservasi koleksi tanaman upacara agama Hindu Bali yang dilakukan Kebun Raya 'Eka Karya' Bali, serta pemanfaatannya dalam masyarakat Bali.

\section{PERKEMBANGAN KOLEKSI TANAMAN UPACARA AGAMA HINDU BALI}

Kegiatan yang dilakukan Kebun Raya Balisebagai upaya konservasi terhadap tanaman upacara agama Hindu Bali adalah melalui kegiatan eksplorasi dan pengkoleksian tanaman. Kegiatan eksplorasi mulai dilakukan tahun 1991 meliputi seluruh kawasan di Bali. Perolehan loleksi dari Kabupaten Badung sebnayak empat nomor, Kabupaten Bangli sebanyak empat nomor, Kabupaten Buleleng sebanyak 11 nomor, Kabupaten Gianyar sebanyak dua nomor, Kabupaten Jenbarana sebanyak sepuluh, Kabupatenn Karangasem sebanyak 11 nomor, Kabupaten Klungkung sebanyak satu nomor dan Kabupaten Tabanan enam nomor. Dari kegiatan eksplorasi tersebut berhasil didapatkan informasi kekayaan jenis tumbuhan yang digunakan dalam upacara oleh masyarakat setempat.

Koleksi tumbuhan yang terdapat di Kebun Raya Baliditanam sebagai koleksi tematik yang terletak pada areal khusus di Vak XVIII.A. di. Koleksi ini yang tertata dalam sebuah taman yang dikenal dengan Taman Panca Yadnya. Koleksi ini terdiri atas tanaman yang digunakan masyarakat Bali dalam upacara agama.

Taman Panca Yadnya mulai ditata tahun 2002 (Gambar 1.) dan berlanjut tahun 2017 (Gambar 2.). Taman Panca Yadnya ditata berdasarkan konsep tata ruang Tri Mandala yaitu Utama Mandala, Madia Mandala dan Nista Mandala. Pada Utama Mandala dibuat bangunan berbentuk bajra/genta tempat dokumen kearifan lokal dan upacara yang sarat dengan pendidikan konservasi, pada Madia Mandala akan dibuat bangunan berbentuk pelataran sebagai tempat atraksi seni dan budaya sedangkan pada bagian Nista Mandala digunakan untuk mengkonservasi tumbuhan yang digunakan dalam upacara agama Hindu Bali.

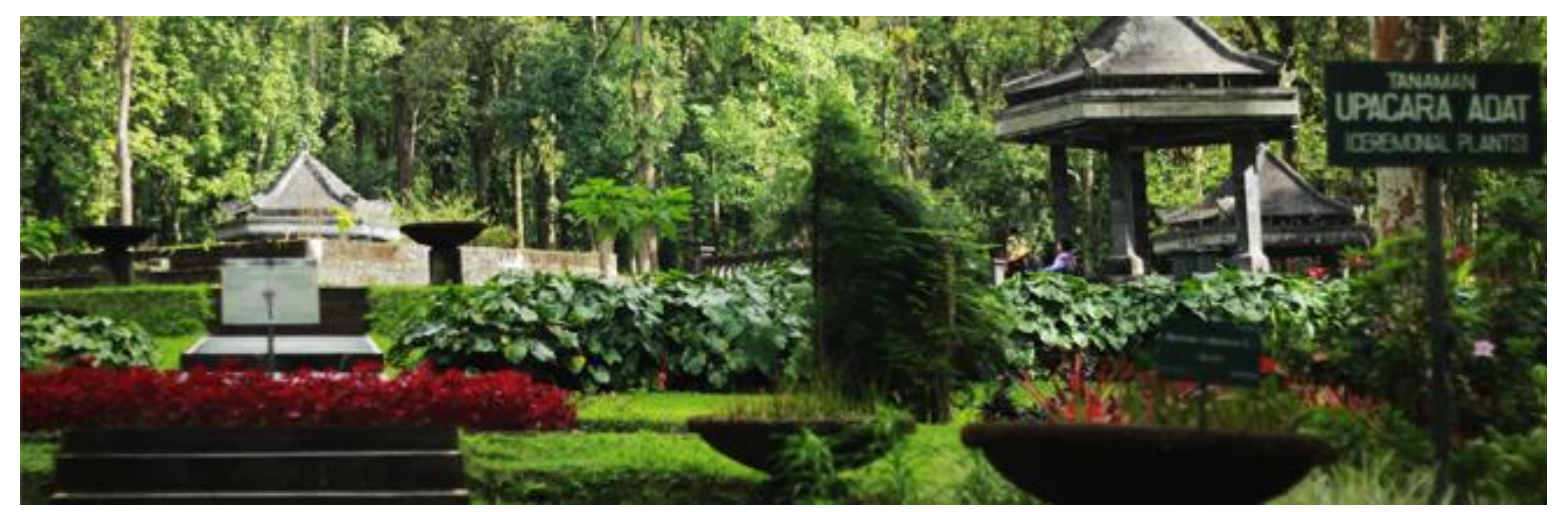

Gambar 1. Awal Penataan Taman Panca Yadnya Kebun Raya Bali 


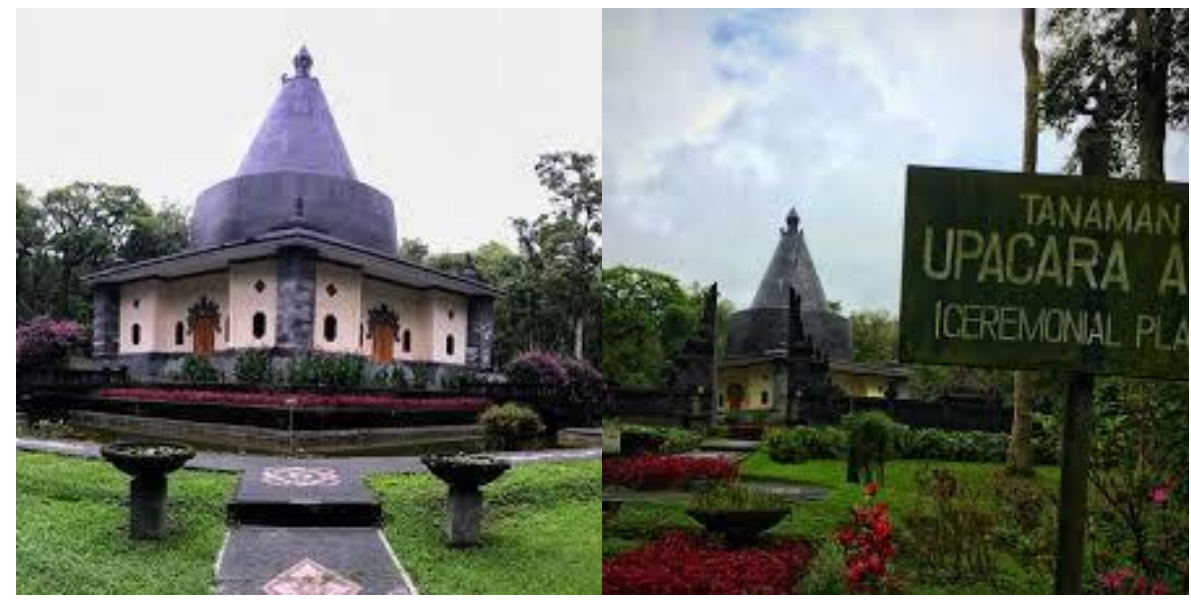

Gambar 2. Taman Panca Yadnya Kebun Raya 'Eka Karya’ Bali

Taman Panca Yadnya merupakan tempat koleksi tanaman yang digunakan untuk Upacara Adat Hindu Bali "Yadnya" yang melibatkan tiga unsur yaitu bunga, api dan air. Yadnya berasal dari kata "Yad" yang artinya menuju keselamatan. Bunga melambangkan Siwa sebagai pelebur. Api simbol Brahma sebagai pencipta. Air simbol Wisnu sebagai pemelihara. Selain bunga, bagian-bagian lain dari tanaman seperti batang, daun, buah, umbi juga biasa digunakan untuk upacara yang tertuju kepada lima kelompok Yadnya, yaitu: Dewa Yadnya, persembahan kepada Ida Sanghyang Widi Wasa/Tuhan Yang Maha Esa; Pitra Yadnya, korban suci kepada leluhur; Rsi Yadnya korban suci untuk memuliakan para Rsi, Pendeta, rohaniawan sebagai pembimbing umat; Manusa Yadnya, korban suci untuk keselamatan umat manusia dari sejak bayi dalam kandungan sampai menikah; dan Bhuta Yadnya, korban suci kepada Bhuta Kala atau mahluk yang lebih rendah tingkatannya dari manusia.

\section{POTENSI TANAMAN UPACARA AGAMA HINDU BALI}

Pengkoleksian tanaman upacara ini disesuaikan dengan habitat Kebun Raya Balidan lebih mengutamakan jenis - jenis yang memiliki status konservasi. Dari 205 jenis tumbuhan upacara yang berhasil dikonservasi, terdapat 30 jenis yang termasuk dalam tanaman yang berstatus konservasi (Redlist IUCN) (Lampiran 1.). Untuk itu masih perlu dilakukan kegiatan konservasi dan penggalian informasi potensi tanaman upacara sehingga dapat dimanfaatkan secara optimal tanpa menyebabkan kepunahan.

Tabel 1. Beberapa Tanaman untuk Upacara Agama Hindu di Bali

\begin{tabular}{|c|c|c|c|c|}
\hline No. & Nama & Nama Daerah & $\begin{array}{l}\text { Bagian } \\
\text { Tanaman }\end{array}$ & Pemanfaatan \\
\hline 1 & Aegle marmelos (L.) Corr. & Bila & buah & Manusa Yadnya \\
\hline 2 & $\begin{array}{l}\text { Amorphophallus paeniifolius (Dennst.) } \\
\text { Nicolson. }\end{array}$ & Suweg & Umbi & $\begin{array}{l}\text { Dewa, Rsi, Pitra, } \\
\text { Manusa, Bhuta } \\
\text { Yadnya }\end{array}$ \\
\hline 3 & Alocasia macrorrhizos (L.) G. Don. & Bekaja & $\begin{array}{c}\text { Daun } \\
\text { dewasa }\end{array}$ & $\begin{array}{l}\text { Manusa, Butha } \\
\text { Yadnya }\end{array}$ \\
\hline 4 & Azadirachta indica A. Juss. & Intaran & Daun & Pitra Yadnya \\
\hline 5 & Colocasia tuberosus Benth.) & Sabrang & Umbi & Manusa Yadnya \\
\hline 6 & Cocos nucifera $\mathrm{L}$ & Kelapa & $\begin{array}{l}\text { tangkai } \\
\text { daun }\end{array}$ & Manusa Yadnya \\
\hline & & & Sabut & Manusa Yadnya \\
\hline 7 & Colocasia esculenta (L.) Schott. & Keladi & Umbi & $\begin{array}{l}\text { Dewa, Pitra, Manusa, } \\
\text { Bhuta Yadnya }\end{array}$ \\
\hline 8 & Colocasia gigantea (Blume) hook.f. & Talas & Daun & Manusa Yadnya \\
\hline
\end{tabular}




\begin{tabular}{|c|c|c|c|c|}
\hline & & & dewasa & \\
\hline 9 & Cordyline terminals bicolor & Andong & Daun & Panca Yadnya \\
\hline 10 & Cycas rumphii Miq. & Paku aji & Daun & Pitra Yadnya \\
\hline 11 & Diplazium esculentum & paku sayur & Akar & Pitra Yadnya \\
\hline 12 & Duno zibettmus Murr & Durian & Daun & Panca Yadnya \\
\hline 13 & Dysoxylum caulostachyum Miq. & Majegau & Batang & Pitra Yadnya \\
\hline 14 & Elaeocharpus grandiflorus J. E. Smith & Rijasa & Bunga & Pitra Yadnya \\
\hline 15 & Erythrina evodiphylla Hassk. & Dlungdung & Ranting & Pitra Yadnya \\
\hline 16 & Homalomena cordata Schott. & Suweg & Umbi & Manusa Yadnya \\
\hline 17 & Jasminum sambac (L) W. Ait & Menuh & Bunga & Pitra Yadnya \\
\hline 18 & Luffa acutangula (L.) Roxb. & Pare & Biji & Manusa Yadnya \\
\hline 19 & Pandanu amaryfolius & Pandan harum & Daun & Panca Yadnya \\
\hline 20 & Piper betle $\mathrm{L}$. & Sirih & Daun & Pitra, Manusa Yadnya \\
\hline 21 & Plumeria acuminata $\mathrm{W}$. T. Ait & Jepun Bali & Bunga & Panca Yadnya \\
\hline 22 & Punica granatum L. & Delima & Daun & Pitra, Manusa Yadnya \\
\hline 23 & Remusatia vivipara (Roxb.) Schott. & Biah ganjah & Umbi & Pitra Yadnya \\
\hline 24 & Salacca edulisReinw & Salak & Daun & Panca Yadnya \\
\hline 25 & Santalum album $\mathrm{L}$ & Cendana & Batang & Pitra Yadnya \\
\hline 26 & $\begin{array}{l}\text { Schimatoglottis calyptara (Roxb.) Zoll. } \\
\text { \& Moritzi }\end{array}$ & Kesesi & Umbi & Manusa Yadnya \\
\hline 27 & Schefflera elliptica (Blume) Harms & Kayu tulak & Daun & Buta Yadnya \\
\hline
\end{tabular}

Kebanyakan tanaman yang digunakan untuk upacara agama tidak bisa digantikan oleh tanaman dari jenis lain. Misalnya meduri putih (Calotropis gigantea R. Br.). Bagian tanaman yang digunakan untuk upacara adalah bunganya. Dalam penggunaannya, bunga merupakan lambang ketulusan dan kesucian pikiran untuk ber-yadnya (Wiana, 2002), walaupun daunnya juga dapat digunakan sebagai penggantinya. Contoh lain adalah biyu agung dan biyu masa bali (Musa paradisiaca L.).

Beberapa jenis tanaman yang sekarang sudah sulit diperoleh antara lain kayu sudamala (Artemesia vulgaris L.), bligo (Benincasa hispida (Thunb.) Cogn.), meduri putih (Calotropis gigantea $\mathrm{R}$. Br.), sandat (Cananga odorata (Lamk) Hook. f. \& Thons.) yang asli dari daerah Bali, cemara geseng (Casuarina junghuhniana Miq.), temu agung (Curcuma sp.), biaung buluh (Dioscorea sp.), pare (Luffa acutangula (L.) Roxb.), kayu teteg (Mecetia sp.), cempaka Wilis yang asli Bali (Michelia sp.), byu gunting (Musa paradisiaca L.), kacang ucu (Pueraria phaseoloides (Roxb.) Bth.), terong bulu (Solanum sp.) dan ketok- tok serta kamaratih (Lestari, 2004).

\section{KESIMPULAN}

Konservasi tanaman upacara agama Hindu Bali di Kebun Raya Balidilakukan melalui kegiatan penelitaian dan pengembangan yang meliputi kegiatan eksplorasi dan pengkoleksian tanaman upacara agama Hindu Bali. Hingga Januari 2020 koleksi tanaman tanaman upacara agama Hindu Bali yang tertata di Taman Panca Yadnya sebanyak 62 suku, 139 marga, 205 jenis dan 1.212 spesimen, yang berasal dari seluruh Bali. Kegiatan penelitian juga telah dilakukan dengan menggali informasi pemanfaatan tanaman upacara agama Hindu Bali sebagai kekayaan pengetahuan lokal masyarakat.

\section{UCAPAN TERIMA KASIH}

Penulis mengucapkan terima kasih kepada seluruh staf Unit Registrasi Koleksi dan Unit Pemelihara Koleksi selama proses penyusunan tulisan ini sehingga dapat berjalan dengan baik dan lancar.

\section{DAFTAR PUSTAKA}


Armeini, W, A. 2018. Tanaman Upakara. http://adiarmaeni.blogspot.com/2018/07/tanaman-upakara.html. Di akses: 2 Februari 2020.

Lestari, W.S. 2004. Pemanfaatabn Tumbuhan Untuk Upacara Agama Hindu Di Beberapa wialyah di Kabupaten Gianyar. Prosiding Seminar Konservasi Tumbuhan Upacara Agama Hindu Bali. Oktober: 273-278.

Sardiana, I Ketut. 2010. Gumi Banten: Unit Pembibitan Tanaman Ritual (Upakara) Lembaga Pengabdian Kepada Masyarakat Universitas Udayana. Majalah Aplikasi Iptek Ngayah 1(1): 13-21.

Warseno, T, N.P.S. Asih dan A. Kurniawan. 2013. Pelestarian Dan Pemanfaatan Jenis-Jenis Araceae Sebagai Tanaman Upacara Agama Hindu Di Kebun Raya "Eka Karya" Bali. Prosiding Seminar Nasional Biodiversitas. Vol: 1. Februari: $115-121$.

Wiana, I K.. 2002. Makna Upacara Yajna dalam Agama Hindu. Cetakan pertama. Paramita. Surabaya.

Lampiran 1. Koleksi Tanaman Usada Kebun Raya Bali yang Memiliki Status Konservasi (dari berbagai sumber)

\begin{tabular}{|c|c|c|c|c|}
\hline No. & Nama Jenis & Suku & Asal Koleksi & $\begin{array}{c}\text { Status Konservasi } \\
\text { IUCN } \\
\text { (www.iucnredlist.org) }\end{array}$ \\
\hline 1 & $\begin{array}{l}\text { Aleurites moluccanus (L.) } \\
\text { Willd. }\end{array}$ & Euphorbiaceae & $\begin{array}{l}\text { Buleleng, } \\
\text { Jembrana, } \\
\text { Karangasem, } \\
\text { Tabanan }\end{array}$ & $\begin{array}{l}\text { Resiko rendah (Least } \\
\text { Concern ver } 3.1 \text { ) }\end{array}$ \\
\hline 2 & Acacia nilotica (L.) Delile & Leguminosae & Badung, Bangli & $\begin{array}{l}\text { Resiko rendah (Least } \\
\text { Concern ver 3.1) }\end{array}$ \\
\hline 3 & Acorus calamus L. & Acoraceae & $\begin{array}{l}\text { Buleleng, Bangli, } \\
\text { Jembrana }\end{array}$ & $\begin{array}{l}\text { Resiko rendah (Least } \\
\text { Concern ver 3.1) }\end{array}$ \\
\hline 4 & Alstonia scholaris (L.) R.Br. & Apocynaceae & Karangasem & $\begin{array}{l}\text { Resiko rendah (Lower } \\
\text { Risk/least concern } \\
\text { ver } 2.3 \text { ) }\end{array}$ \\
\hline 5 & $\begin{array}{l}\text { Artocarpus elasticus Reinw. } \\
\text { ex Blume }\end{array}$ & Moraceae & Tabanan & $\begin{array}{l}\text { Resiko rendah (Least } \\
\text { Concern ver 3.1) }\end{array}$ \\
\hline 6 & $\begin{array}{l}\text { Boesenbergia rotunda (L.) } \\
\text { Mansf. }\end{array}$ & Zingiberaceae & Gianyar & $\begin{array}{l}\text { Resiko rendah (Least } \\
\text { Concern ver 3.1) }\end{array}$ \\
\hline 7 & $\begin{array}{l}\text { Breonia chinensis (Lam.) } \\
\text { Campuron }\end{array}$ & Rubiaceae & Jembrana & $\begin{array}{l}\text { Resiko rendah (Least } \\
\text { Concern ver 3.1) }\end{array}$ \\
\hline 8 & Caryota mitis Lour. & Arecaceae & $\begin{array}{l}\text { Buleleng, } \\
\text { Jembrana }\end{array}$ & $\begin{array}{l}\text { Resiko rendah (Least } \\
\text { Concern ver } 3.1 \text { ) }\end{array}$ \\
\hline 9 & Ceiba pentandra (L.) Gaertn. & Malvaceae & Jembrana & $\begin{array}{l}\text { Resiko rendah (Least } \\
\text { Concern ver 3.1) }\end{array}$ \\
\hline 10 & Cycas rumphii Miq. & Cycadaceae & - & $\begin{array}{l}\text { Terancam (Near } \\
\text { Threatened ver } 3.1 \text { ); } \\
\text { Appendix II, CITES }\end{array}$ \\
\hline 11 & Dracaena sp. & Asparagaceae & Buleleng & Appendix II, CITES \\
\hline 12 & $\begin{array}{l}\text { Elaeocarpus bojeri } \\
\text { R.E.Vaughan }\end{array}$ & Elaeocarpaceae & Tabanan & $\begin{array}{l}\text { Kritis (Critically } \\
\text { Endangered D ver } 2.3 \text { ) }\end{array}$ \\
\hline 13 & $\begin{array}{l}\text { Euonymus indicus B.Heyne ex } \\
\text { Wall. }\end{array}$ & Celastraceae & Jembrana & $\begin{array}{l}\text { Resiko rendah (Lower } \\
\text { Risk/least concern } \\
\text { ver } 2.3 \text { ) }\end{array}$ \\
\hline 14 & Euphorbia sp. & Euphorbiaceae & Karangasem & Appendix II, CITES \\
\hline 15 & Gossypium barbadense L. & Malvaceae & Karangasem & $\begin{array}{l}\text { Resiko rendah (Least } \\
\text { Concern ver } 3.1 \text { ) }\end{array}$ \\
\hline 16 & $\begin{array}{l}\text { Hiptage benghalensis (L.) } \\
\text { Kurz }\end{array}$ & Malpighiaceae & Karangasem & $\begin{array}{l}\text { Resiko rendah (Least } \\
\text { Concern ver 3.1) }\end{array}$ \\
\hline 17 & Maesopsis eminii Engl. & Rhamnaceae & Tabanan & $\begin{array}{l}\text { Resiko rendah (Least } \\
\text { Concern ver 3.1) }\end{array}$ \\
\hline
\end{tabular}




\begin{tabular}{|c|c|c|c|c|}
\hline 18 & $\begin{array}{l}\text { Magnolia champaca (L.) } \\
\text { Baill. ex Pierre }\end{array}$ & Magnoliaceae & Karangasem & $\begin{array}{l}\text { Resiko rendah (Least } \\
\text { Concern ver 3.1) }\end{array}$ \\
\hline 19 & Magnolia liliifera (L.) Baill. & Magnoliaceae & Karangasem & $\begin{array}{l}\text { Resiko Rendah (Least } \\
\text { Concern ver 3.1; } \\
\text { Appendix III), CITES }\end{array}$ \\
\hline 20 & Mangifera odorata Griff. & Anacardiaceae & Badung & $\begin{array}{l}\text { Data tidak lengkap (Data } \\
\text { Deficient ver 2.3) }\end{array}$ \\
\hline 21 & Matthaea sancta Blume & Monimiaceae & Parigi Moutong & $\begin{array}{l}\text { Resiko rendah (Lower } \\
\text { Risk/least concern } \\
\text { ver } 2.3 \text { ) }\end{array}$ \\
\hline 22 & Morus alba $\mathrm{L}$. & Moraceae & Buleleng, Bangli & $\begin{array}{l}\text { Resiko rendah (Least } \\
\text { Concern ver 3.1) }\end{array}$ \\
\hline 23 & Nerium oleander L. & Apocynaceae & $\begin{array}{l}\text { Buleleng, } \\
\text { Karangasem }\end{array}$ & $\begin{array}{l}\text { Resiko rendah (Least } \\
\text { Concern ver 3.1) }\end{array}$ \\
\hline 24 & Phaleria octandra (L.) Baill. & Thymelaeaceae & Jembrana & $\begin{array}{l}\text { Resiko rendah (Least } \\
\text { Concern ver } 3.1 \text { ) }\end{array}$ \\
\hline 25 & Plumeria rubra $\mathrm{L}$. & Apocynaceae & $\begin{array}{l}\text { Buleleng, Bangli, } \\
\text { Jembrana, } \\
\text { Klungkung }\end{array}$ & $\begin{array}{l}\text { Resiko rendah (Least } \\
\text { Concern ver 3.1) }\end{array}$ \\
\hline 26 & Punica granatum $\mathrm{L}$. & Lythraceae & Badung, Buleleng & $\begin{array}{l}\text { Resiko rendah (Least } \\
\text { Concern ver 3.1) }\end{array}$ \\
\hline 27 & Sambucus javanica Blume & Adoxaceae & Jembrana & $\begin{array}{l}\text { Resiko rendah (Least } \\
\text { Concern ver 3.1) }\end{array}$ \\
\hline 28 & $\begin{array}{l}\text { Schefflera elliptica (Blume) } \\
\text { Harms }\end{array}$ & Araliaceae & $\begin{array}{l}\text { Tabanan, Badung, } \\
\text { Buleleng, } \\
\text { Karangasem }\end{array}$ & $\begin{array}{l}\text { Resiko rendah (Least } \\
\text { Concern ver } 3.1 \text { ) }\end{array}$ \\
\hline 29 & $\begin{array}{l}\text { Senna surattensis (Burm.f.) } \\
\text { H.S.Irwin \& Barneby }\end{array}$ & Leguminosae & Gianyar & $\begin{array}{l}\text { Resiko rendah (Least } \\
\text { Concern ver 3.1) }\end{array}$ \\
\hline 30 & Solanum rudepannum Dunal & Solanaceae & Jembrana & $\begin{array}{l}\text { Resiko rendah (Least } \\
\text { Concern ver 3.1) }\end{array}$ \\
\hline
\end{tabular}

